\title{
Pattern of money allocation in experimental games supports the stress hypothesis of gender differences in Toxoplasma gondii-induced behavioural changes
}

\author{
Jitka Lindová ${ }^{1,3}$, Aleš A. Kuběna ${ }^{1}$, Hana Šturcová ${ }^{2}$, Romana Křivohlavá $^{2}$, Martina Novotná $^{2}$, Anna Rubešová $^{3}$, \\ Jan Havlíček ${ }^{3}$, Petr Kodym ${ }^{4}$ and Jaroslav Flegr ${ }^{1}$ \\ ${ }^{1}$ Department of Philosophy and History of Science, ${ }^{2}$ Department of Parasitology, Faculty of Science, Charles University, Viničná 7 , \\ 12844 Prague, Czech Republic; \\ ${ }^{3}$ Department of Anthropology, Faculty of Humanities, Charles University, Prague, Czech Republic; \\ ${ }^{4}$ National Reference Laboratory for Toxoplasmosis, National Institute of Public Health, Prague, Czech Republic
}

\begin{abstract}
Latent toxoplasmosis has been previously found to cause behavioural and personality changes in humans, which are specific for each gender. Here we tested the stress hypothesis of these gender differences based on the assumption that latent toxoplasmosis causes long-term subliminal stress. In line with this hypothesis, the gender difference will appear specifically in situations with interpersonal context because in contrast to the typical individualistic coping style of men, women have a tendency to express elevated prosocial behaviour under stress. Altogether 295 biology students (29/191 females and 27/104 males infected by T. gondii) played a modified version of the Dictator Game and the Trust Game. As predicted, a gender difference in the effect of latent toxoplasmosis was found for the measure of reciprocal altruism in the Trust Game $(p=0.016)$, but both genders appeared less generous when infected in the Dictator Game modified to minimize social connotation $(p=0.048)$.
\end{abstract}

Keywords: Toxoplasma, stress hypothesis, experimental games, coping, gender differences

Toxoplasma gondii is a cosmopolitan protozoan parasite. Felids represent the final hosts, and all warm-blooded animals can serve as intermediate hosts. After a short period of acute toxoplasmosis immediately after infection (lasting several weeks in humans), the parasite encysts and the parasitosis changes to the life-long latent stage. The prevalence of latent toxoplasmosis in the Czech Republic is about $30 \%$, with the rate being up to $60 \%$ in other European countries and even higher in some developing countries.

Toxoplasma gondii in its latent stage of infection is known to change the behaviour of rodents. In a majority of cases, these changes seem to have a character of lower ability to discriminate between novel and familiar stimuli (Hodková et al. 2007a), and are usually considered results of the manipulative activity of the parasite aimed to increase the probability of being transmitted to the definitive host by predation (Holmes and Bethel 1972).

Behavioural changes induced by this parasite were also found in humans; however, here the applicability of the manipulation hypothesis has been questioned a) because humans are not preyed by felids (Webster 2001) and b) because there are striking gender differences in the observed behavioural changes (but see Lindová et al. 2006).
The first studies aimed to reveal the pattern of psychological changes in humans used Cattell's 16 Personality Factor Questionnaire (16PF) and found an opposite T. gondii-induced shift in men and women in four personality factors, namely factors A (the high pole of this dimension can by characterized e.g. as warmth), G (rule consciousness), L (vigilance, mistrust), and Q3 (self-control, self-image) (Flegr et al., 1996). More specifically, infected men scored significantly lower in factor $\mathrm{G}$ (disregards rules, expedient), higher in factor L (suspecting, jealous, dogmatic), and non-significantly lower in factors A (reserved, detached, critical) and Q3 (uncontrolled, lax, follows own urges) (Flegr and Hrdý 1994, Flegr et al. 1996). Infected women scored significantly higher in factor A (warm-hearted, outgoing), non-significantly higher in factors $\mathrm{G}$ (conscientious, persistent, moralistic, staid), Q3 (controlled, exacting will power, socially precise), and significantly lower in factor L (trusting, accepting conditions, tolerant) (Flegr et al. 1996). In a later study using a set of simple behavioural experiments, some of the effects were verified behaviourally: men and women were found to be inversely influenced by $T$. gondii, where infected women were found to be more self-controlled (responsible, having tidy habits, painstaking) and tidily 
dressed than uninfected women, and infected men were found to have fewer and less intensive relationships, to be less self-controlled (more lax, slovenly) and more untidily dressed than uninfected men (Lindová et al. 2006).

The mechanism of the effect of latent toxoplasmosis on human behaviour is unknown; however, we have some indices of deteriorated physical functioning in $T$. gondiiinfected subjects. These include prolonged simple reaction times (Havlíček et al. 2001, Novotná et al. 2008), and higher risk of traffic accidents (Flegr et al. 2009, Kocazeybek et al. 2009) in infected subjects. Deteriorated physical functioning of $T$. gondii-infected subjects possibly leading to shorter life expectancy could also explain the unexpected phenomenon of decreased seropositivity in the highest age groups in many prevalence studies (e.g. Kodym et al. 2001). One possible explanation of these observed gender differences in influence of $T$. gondii on humans has been proposed in the terms of the stress hypothesis which suggests that latent toxoplasmosis, via deteriorated physical functioning, induces mild and long-term stress and we can observe psychological changes that are behavioural displays of more pronounced gender different coping styles (Lindová et al. 2006). Originally, problem-focused coping style and emotion-focused coping was considered typical of men and women, respectively (Folkman and Lazarus 1980, Billings and Moos 1981, 1984, Endler and Parker 1990, Stone and Neale 1984). More recent research deemphasizes this difference and stresses the importance of the social dimension, instead (Rosario et al. 1988, Hobfoll et al. 1994, Tamres et al. 2002). In contrast to men, who seem to use more individualistic and antisocial (e.g. aggressive, hostile) forms of coping (Carver et al. 1989, Hobfoll et al. 1994), women are more likely to seek and provide social support (Stone and Neale 1984, Rosario et al. 1988, Carver et al. 1989), join with others (Hobfoll et al. 1994), verbalize towards others or the self (Tamres et al. 2002). A recent biological (evolutionary) theory similarly distinguishes between the male "fight-or-flight" response and the female "tend-and-befriend" reaction to stress (Taylor et al. 2000) following from the strong need of women to protect children and maintain social relationships. Although this theory is primarily designed for the situation of acute stress, it can be probably applied to chronic stress as well, where coping behaviour could be expected to become a permanent constituent of behaviour and personality of infected subjects.

Here we test the stress hypothesis by inducing an "economic" versus "social" situation using experimental games where the subjects decide how much money to allocate to another player. In the "social" situation, but not in the "economic" situation, we expect to observe a gender difference in $T$. gondii-induced shifts in behaviour, which would be in line with the gender typical coping styles, i.e. we expect the behaviour of infected subjects compared to uninfected subjects to be shifted towards more individu- alistic (asocial/antisocial) behaviour in men and towards more prosocial behaviour in women.

For testing this prediction, we chose two experimental games which differ in the underlying motivations for players' money allocations.

Dictator Game is believed to be a measure of altruism that is neither a response to someone's prior generosity nor is expected to be reciprocated (Cox and Deck 2006). To further decrease social and emotional motivation (i.e. tendency to reciprocate, sympathy) for money allocations in this game, here the game was not played only once but 12 times (i.e. it had 12 rounds); the roles of dictators and recipients were switched every round (each subject played 6 rounds in each of the roles) and each subject's opponent was randomly chosen de novo every round. So the recipient was distracted between several people and thus final payoffs of the individual subject's opponents were practically independent from the subject's money allocation. We did not have any specific prediction regarding behaviour of infected and uninfected subjects.

In the Trust Game where players are active in each of the roles, behaviour of the first player (investor) is considered to reflect trust of the first player in the second player, the recipient, and the return of the recipient is mostly explained as reciprocal altruism (Croson and Buchan 1999). Women seem to tend to interpret this game more communally and empathically and thus to repay trust with trustworthiness in return more than men (Geanakoplos et al. 1989, Guerra and Zizzo 2004). This is hypothesized to be even more accentuated under the long-term influence of the stressor such as latent $T$. gondii infection due to the prosocial coping style. Therefore, we expect infected women to return relatively more than uninfected women. In men, in contrast, as a consequence of their more individualistic coping style, we expect to find rather economical behaviour in infected subjects, i.e. returning less money.

To enable comparison with the modified version of the Dictator Game, the Trust Game was also played repeatedly. In this case, we did not expect any important shifts in the psychological motives of money allocations due to repeatedness. To sum up, we expected a gender difference to appear in the reciprocal returning of the recipient in the Trust Game but not in the Dictator Game.

\section{MATERIALS AND METHODS}

Subjects. The studied sample consisted of 295 Czech and Slovak healthy undergraduate biology students at the Charles University, Prague. Twenty-nine out of 191 females and 27 out of 104 males were Toxoplasma-positive. The mean age was 22.6 (s.d.=2.0) for females and 22.2 (s.d.=2.2) for males. All subjects were asked to voluntarily participate in the research project and to sign an informed consent form. The recruitment of the study subjects and data handling practices complied with the Czech regulations in force. 
Immunological tests for toxoplasmosis. Specific anti-Toxoplasma IgG in all subjects and IgM antibodies concentrations in high IgG subjects were determined by ELISA (IgG: SEVAC, Prague; IgM: TestLine, Brno), optimized for early detection of acute toxoplasmosis (Pokorný et al. 1989), and the complement fixation test (CFT) (SEVAC, Prague) which is more robust to temporal fluctuations of the immune system status and therefore more suitable for the detection of old $T$. gondii infections (Warren and Sabin 1942). The titre of anti-Toxoplasma antibodies in sera was measured in dilutions between 1:8 and 1:1024. Subjects with negative results of IgM ELISA (positivity index $<0.9$ ) and having CFT titres higher than 1:8 were considered latent-toxoplasmosis positive. There were no high-IgM (acutely infected) subjects in our sample.

Procedure. The experiment was double blind - neither the subjects nor the experimenters knew which subjects were infected with $T$. gondii. The behavioural testing sessions were performed in the period from summer 2004 to winter 2006 on working days starting at $9 \mathrm{a} . \mathrm{m}$. Twelve subjects were invited for one session, with 6 of them being instructed to come at 9 a.m. and the other 6 to come at 9.15. The first 6 subjects were seated in individual boxes equipped with computers in the distal part of the experimental room. The other 6 subjects were similarly seated in individual boxes in the part of the experimental room close to the entrance door. To further minimize the possibility of contact between the two groups, the two parts of the room were separated by a screen and the subjects were instructed not to speak loudly. Inside the group, the subjects could partly see each other, but could never see anyone else's computer monitor. After all subjects arrived, they were given general instructions by the experimenter about the use of the experimental software. They were encouraged to ask whenever they are not sure to understand the rules of the game properly, and were told to be given the money they would win immediately after the end of the testing session.

The subjects played two games - the Dictator Game and the Trust Game. In the Dictator Game, the Dictator had to divide CZK 10 (about \$0.5) between her/himself and another player, called Serf. The Serf could see how much he/she was given by the Dictator, and always had to accept. In the Trust Game, the first player, Investor, received CZK 10 from the experimenter and then could send between 0 and 10 to the other player called Businessman. On the way, the experimental software tripled the amount sent $(y)$, so that the Businessman received $3 y$. Then the Businessman was free to return anything between 0 and $3 y$ to the Investor. The Investor could see how much he was returned, and had to accept. His payoff then was $10-y+z$ where $z$ is the amount returned by the Businessman to the Investor. The two games were played consecutively, with the Dictator Game coming first. Each game was repeated 12 times. The subjects were alternately assigned to each of the roles in the game, so that each subject played each role 6 times. The players were informed that the couples of opponents were newly formed every round, so that everyone had a new opponent every round. Subjects from the distal part of the experimental room always played against subjects in the other part of the room. Thus the subjects remained unaware of the identity of their opponents and, at the same time, did not doubt to be playing with real opponents and not with a computer.
Statistical analyses. The experimental software stored information about all steps performed by the players. As a measure of generosity in the Dictator Game for round $i+1$, the difference between the sum of money received in round $i$ and the money given in round $i+1$ was computed. This takes into account individual subjects' game histories and thus is a better measure than the absolute sum of money allocated. This variable was called diff. To calculate the effect of Toxoplasma on diff, we performed partial Kendall's correlation. A nonparametric test was used because we expected non-normal distribution of diff. Although Kendall's test is a correlation measure, it can be used in situations where one or two variables are binary. The advantage of this test is that a second variable can be partialled out, which in our analyses was the age of subjects. Age was included in the analysis because we expected it to have a strong effect on subjects' financial situation and attitude towards money. Only 5 rounds for each subject entered the model: diff for the first round could not be computed because it was preceded by no other round. To test if Toxoplasma-positive and Toxoplasmanegative subjects differ in their overall behaviour in the Dictator Game, we used repeated measures General Linear Models (GLM). GLM is not sensitive to slight non-normality of data. As the dependent variable, repeatedly measured diff was entered. The other variables entering the analysis were age, Toxoplasma, sex and Toxoplasma-sex interaction.

In the Trust Game, "trust" of the first player, Investor, was measured using repeated measures GLM performed with the sum of money invested by Investor in 6 rounds as the dependent variable, and Toxoplasma, sex, age and Toxoplasma-sex interaction as independent variables.

As a measure of reciprocal altruism in the Trust Game, "relative residuals" of returned sums of money were computed for each round. Relative residual for a player $k$ and round $i$ was computed as a relative difference (controlled for the range of possible sums to return) between the sum returned by a Businessman $k$ in round $i$ and the average returned sum through all players (Businessmen) who had received the same sum from the Investor. Repeated relative residuals were entered as the dependent variable and Toxoplasma, sex, age and Toxoplasmasex interaction as independent variables. Subjects who received CZK 0 and therefore could not have returned anything in any round, were excluded from the analysis.

To analyze the effect of Toxoplasma or Toxoplasma-sex interaction on generosity of subjects through both experimental games, we used multivariate General Linear Models. Two dependent variables entered the model: average of $5 \operatorname{diff}$ (for the Dictator Game) and average of 6 relative residuals (for the Trust Game).

\section{RESULTS}

\section{Dictator Game}

In Kendall's analysis of the Dictator Game, diff was significantly affected by Toxoplasma in rounds 2 through 5 (for details see Table 1). Diff 6 did not differ between Toxoplasma-positive and Toxoplasma-negative subjects.

In the repeated measures GLM, the effect of Toxoplas$m a$ on repeated diff approached significance $\left(F_{1,290}=3.44\right.$; $\left.p=0.065 ; \eta^{2}=0.012\right)$. The effect of Toxoplasma- 
sex interaction on repeated diff was non-significant $\left(F_{1,290}=0.43 ; p=0.51 ;\right.$ Fig. 1$)$.

Table 1. Partial Kendall's correlation of latent toxoplasmosis status with diff controlled for age of subjects.

\begin{tabular}{lrrrrr}
\hline $\mathrm{n}=295$ & diff2 & diff3 & diff4 & diff5 & diff6 \\
\hline Partial correlation & -0.086 & -0.085 & -0.086 & -0.084 & 0.020 \\
Asymptotic $p$-value & 0.027 & 0.029 & 0.027 & 0.031 & 0.601 \\
\hline
\end{tabular}

\section{Trust Game}

In the Trust Game, the effect of Toxoplasma on relative residuals (the measure of the Businessman's willingness to return) was not significant $\left(F_{1,203}=2.23 ; p=0.14\right)$. The effect of Toxoplasma-sex interaction on relative residuals approached significance $\left(F_{1,203}=3.19 ; p=0.076\right.$; $\eta^{2}=0.015$; Fig. 2).

The effect of Toxoplasma or Toxoplasma-sex interaction on the money invested in the Trust Game was nonsignificant (for Toxoplasma: $F_{1.278}=0.057 ; p=0.82$, for Toxoplasma-sex interaction: $F_{1,278}=0.00 ; p=0.99$ ).

Multivariate General Linear Models with two dependent variables - average of 5 diff (for the Dictator Game) and average of 6 relative residuals (for the Trust Game) - revealed a significant effect of Toxoplasma-sex interaction $\left(F_{1,202}=3.09 ; p=0.048 ; \eta^{2}=0.030\right)$, but not of Toxoplasma $\left(F_{1,202}=2.23 ; p=0.11 ; \eta^{2}=0.022\right)$. In a more detailed analysis of between subject effects in this multivariate GLM, the difference between the allocation in the Dictator Game and the return in the Trust Game was confirmed. For the Dictator Game, the effect of Toxoplasma reached the level of statistical significance $\left(F_{1,203}=3.954 ; p=0.048 ; \eta^{2}=0.019\right)$ in contrast to the effect of Toxoplasma-sex interaction $\left(F_{1,203}=1.10\right.$; $\left.p=0.30 ; \eta^{2}=0.005\right)$, whereas for the Trust Game, it was the effect of Toxoplasma-sex interaction that was significant $\left(F_{1,203}=5.89 ; p=0.016 ; \eta^{2}=0.028\right)$ in contrast to the effect of Toxoplasma $\left(F_{1,203}=0.09 ; p=0.77 ; \eta^{2}<0.001\right)$.

\section{DISCUSSION}

Our study brings further evidence of specific behavioural changes in humans induced by latent toxoplasmosis. Most importantly, multivariate GLM confirmed our hypothesis of gender different behavioural shifts in infected subjects, which are consistent with gender-typical coping styles with stress (individualistic/antisocial versus prosocial in men and women, respectively). More specifically, men were found to be less generous (give less money) when infected, but this was not the case for women. Secondly, we found a pattern different in the Dictator Game from that in the Trust Game; whereas in the Trust Game the results were as above mentioned, in the Dictator Game, infected subjects of both genders behaved less generously than uninfected subjects of the same gender.

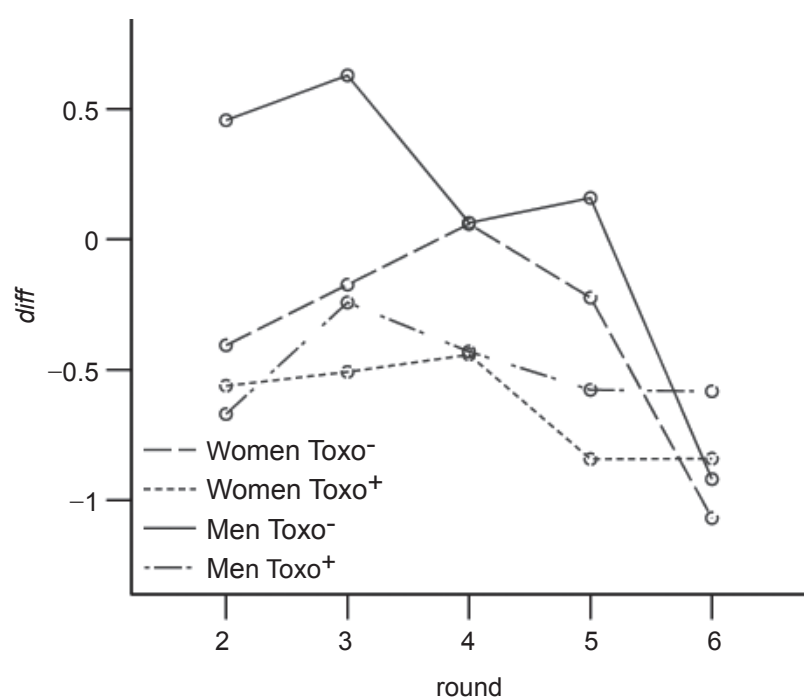

Fig. 1. Generosity of men and women infected or uninfected by Toxoplasma gondii in the 2nd through 6th round of modified Dictator Game. Abbreviations: diff - measure of generosity; Toxo $^{-}-T$. gondii-uninfected subjects; Toxo $^{+}-T$. gondiiinfected subjects.

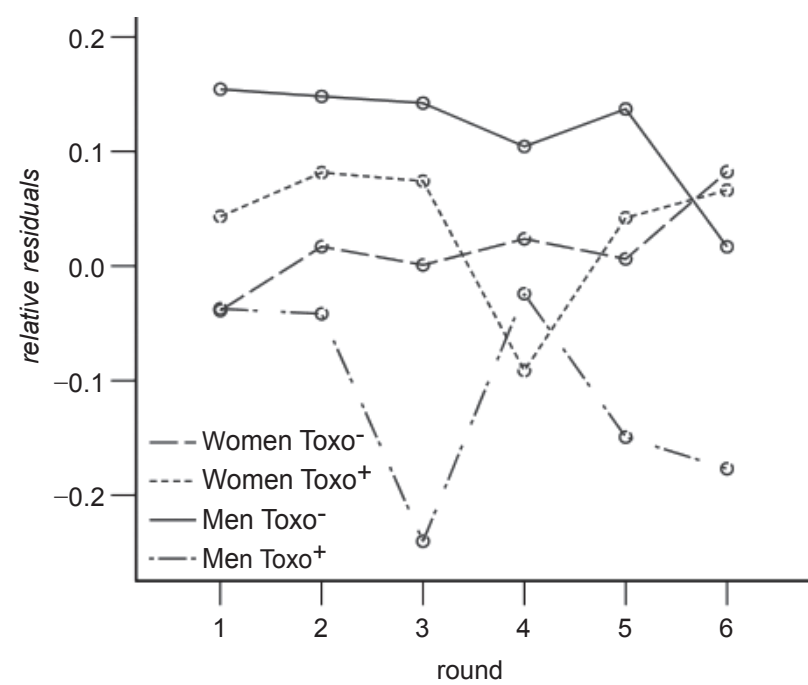

Fig. 2. Generosity of men and women infected or uninfected by Toxoplasma gondii according to returning in 6 rounds of the Trust Game. Abbreviations: relative residuals - measure of generosity; Toxo- $-T$. gondii-uninfected subjects; Toxo $^{+}-T$. gondii-infected subjects.

In other words, we found that while in men latent toxoplasmosis leads to socially negative behaviour regardless of type of the situation, in women the same effect is limited to situations which do not include an interpersonal aspect. In situations where people have the possibility to form reciprocal relationships (as in the Trust Game) we 
can even observe a tendency to be more generous when infected in women.

Our data, of course, provide only indirect support for the stress hypothesis. Use of a more direct instrument (e.g. any questionnaire measuring the level of perceived stress) could be however, in our opinion, rather problematic, as the subjects cannot identify the cause of their stress, and even the stress experience itself need not be conscious. However, we suggest that future use of well-being questionnaires or instruments for measuring subjects' mood could yield interesting results.

A stress-inducing role of toxoplasmosis was also proposed by James (2008), who aimed to explain effects as morphometrical changes in infected subjects (perceived facial dominance, second-to-fourth-digit ratio, Flegr et al. 2005, Hodková et al. 2007b) and changes in sex ratio of offspring of infected women (Kaňková et al. 2007). This theory is based on proposed decrease of testosterone levels in infected men and increase in infected women. However, the opposite (an increase in men and decrease in women) was found by Flegr and colleagues (2008).

Also, the stress hypothesis is not the only explanation which can be used to interpret results obtained in studies on T. gondii-induced changes in humans. Some findings rather point to the possibility that effects of toxoplasmosis could be similar to low-dose drug abuse. These are e.g. higher dopamine in infected rodents and humans (Stibbs 1985, Novotná et al. 2005, Skallová et al. 2006), association of toxoplasmosis with schizophrenia (e.g. Torrey and Yolken 2003), prolonged reaction times (Havlíček et al. 2001, Novotná et al. 2008), and higher risk of traffic accidents (Flegr et al. 2009, Kocazeybek et al. 2009).

Our second finding, decreased helping of infected subjects in the Dictator Game, can be linked to lower wellbeing or impaired mood following from chronical stress and physical deterioration. Well-being and mood have been proven several times to determine the way people interpret and respond to diverse (typically neutral) stimuli and situations inclusive of how much they are willing to help. A number of studies have provided evidence that good mood increases helping (e.g. Berkowitz and Connor 1966, Isen 1970, Isen and Levin 1972, Isen et al. 1973, 1976, Moore et al. 1973, Rosenhan et al. 1974, Levin and Isen 1975). In contrast, an important negative predictor of helping was found to be time stress (Darley and Batson 1973). Other studies provide evidence that positive emotions are associated with positive expectations considering neutral events and with more active approach to common things of interest (e.g. Batson et al. 1979, Isen et al. 1991, 1992, Kahn and Isen 1993). Therefore, we can interpret the smaller allocations of $T$. gondii-infected individuals as their tendency to interpret the game as a less positive situation and their lesser interest in the game, lesser activity and less positive responding.
We did not find any difference between infected and uninfected subjects in the trusting behaviour. Possibly, this can be explained by distinct tactics used to maximize own payoff in the game: keeping the sum for myself and not investing anything, which maximizes own payoff relatively to others' payoff, versus investing everything, which maximizes collective payoff and consequently own absolute payoff. Men probably pursue the first of these tactics more often than women, who insist more on equal payoffs of both players (Andreoni and Vesterlund 2001). It could be possible that in men, $T$. gondii infection does not specifically strengthen one of these tactics to maximize own payoff, but perhaps both of them. Therefore, we cannot see any difference in mean generosity between infected and uninfected men, but we should be able to see increased variability in infected subjects. However, in a post hoc analysis of variance, we did not find any differences in variability between infected and uninfected men. For women, it can be that apart from prosocial tendencies, other variables such as risk proneness are also influenced by $T$. gondii infection. We have to keep in mind that women are also thought to behave more passively under stress than men, e.g. demonstrating avoidance or cautiousness (Billings and Moos 1984, Stone and Neale 1984, Endler and Parker 1990, Hobfoll et al. 1994). Therefore, decreased risk proneness of infected women may counteract their increased tendency to act prosocially.

Alternative explanation for negative results in investing in the Trust Game is that this measure is too weak to identify changes induced by $T$. gondii. In contrast to the other two measures (diff and relative residuals) which measured the subjects' behaviour relative to the previous opponent's action, here we compared the absolute sums of money invested without taking into account the game history. Because the specific behaviour in this game played repeatedly can be expected to depend strongly on the game history, comparing the absolute behaviour may not represent a robust measure.

Although the results obtained basically confirm our hypothesis, they are not very strong in effect. A reason for the somewhat weaker results could be the experimental design where each subject was tested in a slightly different situation due to specific composition of groups of subjects tested together during one session. If subjects had been tested with virtual co-players pre-programmed to behave identically, we would have gotten less variable data where effects of toxoplasmosis would most likely appear more clearly. However, it has often been stressed that in experimental games authenticity is amongst the key factors leading to valid results (e.g. Camerer and Fehr 2004), therefore we chose the more variable design without deception about co-player identities.

Our results corroborate the stress hypothesis of genderspecific behavioural response to toxoplasmosis (Lindová 
et al. 2006) and provide experimental support for the notion that although not manifesting clearly distinguishable symptomathology, latent toxoplasmosis could play an important role in people's quality of life and their behaviour towards the social environment (Flegr et al. 1996). In addition to psychomotor impairment indicated by previous findings, the present study shows another serious impact of $T$. gondii and revives the question of expedience of treatment of latent toxoplasmosis.

Acknowledgements. This research was supported by grant No. 406/07/0581 of the Grant Agency of the Czech Republic and grant No. 0021620828 of the Czech Ministry of Education, Youth and Sports.

\section{REFERENCES}

Andreoni J., Vesterlund L. 2001: Which is the fair sex? Gender differences in altruism. Q. J. Econ. 116: 293-312.

Batson C.D., Coke J.S., Chard F., Smith D., Taliaferro A. 1979: Generality of the "Glow of Goodwill": effects of mood on helping and information acquisition. Soc. Psychol. Q. 42: 176-179.

Berkowitz L., Connor W.H. 1966: Success, failure and social responsibility. J. Pers. Soc. Psychol. 4: 664-669.

Billings A.G., Moos R.H. 1981: The role of coping responses and social resources in attenuating the stress of life events. J. Behav. Med. 4: 139-157.

Billings A.G., Moos R.H. 1984: Coping, stress and social resources among adults with unipolar depression. J. Pers. Soc. Psychol. 46: 877-891.

Camerer C.F., Fehr E. 2004: Measuring social norms and preferences using experimental games: a guide for social scientists. In: J. Heinrich, R. Boyd, S. Bowles, C. Camerer, E. Fehr, H. Gintis (Eds.), Foundations of Human Sociality. Oxford University Press, Oxford, pp. 55-96.

Carver C.S., Scheir M., Weintraub J.K. 1989: Assessing coping strategies: a theoretically based approach. J. Pers. Soc. Psychol. 56: 267-283.

Cox J.C., Deck C.A. 2006: When are women more generous than men? Econ. Inq. 44: 587-598.

Croson R., Buchan N. 1999: Gender and culture: international experimental evidence from Trust Games. Am. Econ. Rev. 89: 386-391.

Darley J.M., Batson C.D. 1973: From Jerusalem to Jericho: a study of situational and dispositional variables in helping behavior. J. Pers. Soc. Psychol. 27: 100-108.

EndLer N.S., PARKER J.D.A. 1990: Stress and anxiety: conceptual and assessment issues. Stress Med. 6: 243-248.

FLEGR J., HRdÝ I. 1994: Influence of chronic toxoplasmosis on some human personality factors. Folia Parasitol. 41: 122-126.

Flegr J., HrušKová M., Hodný Z., Novotná M., Hanušová J. 2005: Body height, body mass index, waist-hip ratio, fluctuating asymmetry and second to fourth digit ratio in subjects with latent toxoplasmosis. Parasitology 130: 621-628.

Flegr J., Klose J., Novotná M., Berenreitterová M., Havlíček J. 2009: Increased incidence of traffic accidents in Toxoplasmainfected military drivers and protective effect $\mathrm{RhD}$ molecule revealed by a large-scale prospective cohort study. BMC Infect. Dis. 9: e72.

Flegr J., Lindová J., Kodym P. 2008: Sex-dependent toxoplasmosis-associated differences in testosterone concentration in humans. Parasitology 135: 427-431.

Flegr J., Zitková Š., Kodym P., Frynta D. 1996: Induction of changes in human behaviour by the parasitic protozoan Toxoplasma gondii. Parasitology 113: 49-54.

Folkman S., LaZARUS R.S. 1980: An analysis of coping in a middle-aged community sample. J. Health Soc. Behav. 21: 219-239.
Geanakoplos J., Pearce D., Stacchetti E. 1989: Psychological games and sequential rationality. Games Econ. Behav. 1: 60-79.

Guerra G., Zizzo D.J. 2004: Trust responsiveness and beliefs. J. Econ. Behav. Org. 55: 25-30.

Havlíček J., Gašová Z., Smith A.P., Zvára K.J., Flegr J. 2001: Decrease of psychomotor performance in subjects with latent "asymptomatic" toxoplasmosis. Parasitology 122: 515-520.

Hobfoll S.E., Dunahoo C.L., Ben-Porath Y., Monnier J. 1994: Gender and coping: the dual-axis model of coping. Am. J. Community Psychol. 22: 49-82.

Hodková H., Kodym P., Flegr J. 2007a: Poorer results of mice with latent toxoplasmosis in learning tests: impaired learning processes or the novelty discrimination mechanism? Parasitology 134: 1329-1337.

Hodková H., Kolbeková P., Skallová A., Lindová J., Flegr J. 2007b: Higher perceived dominance in Toxoplasma infected men - a new evidence for role of increased level of testosterone in toxoplasmosis-associated changes in human behavior. Neuroendocrinol. Lett. 28: 110-114.

Holmes J., Bethel W.M. 1972: Modification of intermediate host behavior by parasites. In: E.U. Canning and D.A. Wright (Eds.), Behavioural Aspects of Parasite Transmission. Academic Press, London, pp. 123-149.

IsEN A.M. 1970: Success, failure, attention, and reactions to others: the warm glow of success. J. Pers. Soc. Psychol. 15: 294301.

Isen A.M., Clark M., Schwarz M.F. 1976: Duration of the effect of good mood on helping: footprints on the sands of time. J. Pers. Soc. Psychol. 34: 385-393.

Isen A.M., Horn N., Rosenhan D.L. 1973: Effect of success and failure on children's generosity. J. Pers. Soc. Psychol. 27: 239-247.

Isen A.M., Levin P.F. 1972: The effect of feeling good on helping: cookies and kindness. J. Pers. Soc. Psychol. 21: 384-388.

Isen A.M., Niedenthal P.M., Cantor N. 1992: The influence of positive affect on social categorization. Motiv. Emotion 16: 65-78.

Isen A.M., Rosenzweig A.S., Young M.J. 1991: The influence of positive affect on clinical problem solving. Med. Decis. Making 11: 221-227.

JAMES W.H. 2008: Further support for the hypothesis that parental hormone levels around the time of conception are associated with human sex ratios at birth. J. Biosoc. Sci. 40: 855-861.

KAHn B.E., Isen A.M. 1993: The influence of positive affect on variety seeking among safe, enjoyable products. J. Consum. Res. 20: 257-270.

KañKová Š., Šulc J., Nouzová K., Fajfrlík K., Frynta D., Flegr J. 2007: Women infected with parasite Toxoplasma have more sons. Naturwissenschaften 94: 122-127.

Kocazeybek B., Oner Y.A., Turksoy R., Babur C., Cakan H., Sahip N., Unal A., Ozaslan A., Kilic S., Saribas S., As- 
lan M., Taylan A., Koc S., Dirican A., Uner H.B., Oz V., Ertekin C., Kucukbasmaci O., Torun M.M. 2009: Higher prevalence of toxoplasmosis in victims of traffic accidents suggest increased risk of traffic accident in Toxoplasma-infected inhabitants of Istanbul and its suburbs. Forensic Sci. Int. 187: 103-108.

Kodym P., Malý M., Švandová E., Ležatková H., Bažoutová M., VlČKovÁ J., Beneš C., ZÁstěra M. 2001: Toxoplasma in the Czech Republic 1923-1999: first case to widespread outbreak. Int. J. Parasitol. 31: 125-132.

Levin P.F., Isen A.M. 1975: Further studies on the effect of feeling good on helping. Sociometry 38: 141-147.

Lindová J., Novotná M., Havlíček J., Jozífková E., Skallová A., Kolbeková P., Hodný Z., Kodym P., Flegr J. 2006: Gender differences in behavioural changes induced by latent toxoplasmosis. Int. J. Parasitol. 36: 1485-1492.

Moore B.S., Underwood B., Rosenhan D.L. 1973: Affect and altruism. Dev. Psychol. 8: 99-104.

Novotná M., Hanusova J., Klose J., Preiss M., Havlicek J., Roubalová K., Flegr J. 2005: Probable neuroimmunological link between Toxoplasma and cytomegalovirus infections and personality changes in the human host. BMC Inf. Dis. 5: e54.

Novotná M., Havlíček J., Smith A.P., Kolbeková P., Skallová A., Klose J., Gašová Z., PísačKa M., Sechovská M., Flegr J. 2008: Toxoplasma and reaction time: role of toxoplasmosis in the origin, preservation and geographical distribution of $\mathrm{Rh}$ blood group polymorphism. Parasitology 135: 1253-1261.

Pokorný J., Fruhbauer Z., Poledñáková S., SÝkora J., ZÁstěra M., Fialová D. 1989: [Assessment of antitoxoplasmatic IgG antibodies with the ELISA method.] Cesk. Epidemiol. 38: 355-361.

Received 20 February 2010
Rosario M., Shinn M., Mørch H., Huckabee C.B. 1988: Gender differences in coping and social supports: testing socialization and role constraint theories. J. Community Psychol. 16: 55-69.

Rosenhan D.L., Underwood B., Moore B.S. 1974: Affect moderates self-gratification and altruism. J. Pers. Soc. Psychol. 30: $546-552$.

Skallová A., Frynta D., Kodym P., Flegr J. 2006: The role of dopamine in Toxoplasma-induced behavioural alterations in mice: An ethological and ethopharmacological study. Parasitology 133: 525-535.

StibBs H.H. 1985: Changes in brain concentrations of catecholamines and indoleamines in Toxoplasma gondii infected mice. Ann. Trop. Med. Parasitol. 79: 153-157.

Stone A.A., Neale J.M. 1984: New measure of daily coping: development and preliminary results. J. Pers. Soc. Psychol. 46: 892-906.

Tamres L.K., Janicki D., Helgeson V. 2002: Sex differences in coping behavior: a meta-analytic review and an examination of relative coping. Pers. Soc. Psychol. Rev. 6: 2-30.

Taylor S.E., Klein L.C., Lewis B.P., Gruenewald T.L., GuRUNG R.A.R., UpdegrafF J.A. 2000: Behavioral responses to stress in females: tend-and-befriend, not fight or flight. Psychol. Rev. 107: 411-429.

Torrey E.F., Yolken R.H. 2003: Toxoplasma gondii and schizophrenia. Emerg. Infect. Dis. 9: 1375-1380.

Warren J., SABin A.B. 1942: The complement fixation reaction in toxoplasmic infection. Proc. Soc. Exp. Biol. Med. 51: 11-16.

Webster J.P. 2001: Rats, cats, people and parasites: the impact of latent toxoplasmosis on behavior. Microbes Infect. 3: 10371045.

Accepted 21 April 2010 